\title{
Correlation for Predicting Water Breakthrough Time in Thin Oil Rim Reservoirs in the Niger Delta
}

\author{
Anietie Okon ${ }^{1, *}$, Dulu Appah², Julius Akpabio ${ }^{1}$ \\ ${ }^{1}$ Chemical and Petroleum Engineering Department \\ University of Uyo, Nigeria \\ ${ }^{2}$ Department of Gas Engineering \\ University of Port Harcourt, Nigeria \\ *Corresponding author's email: anietieokon [AT] uniuyo.edu.ng
}

\begin{abstract}
In the Niger Delta, available correlations to predict water breakthrough time in thin oil rim reservoirs are based on generic reservoir models and/or experimental design approach. This approach had not considered the heterogeneity of the reservoir. Thus, the prediction of these available correlations for thin oil rim reservoirs in the Niger Delta is in doubt, considering the sensitive nature of developing thin oil rim reservoirs. Then, a correlation for water breakthrough time $\left(t_{b t}\right)$ was developed based on integrated reservoir model of thin oil rim reservoir in the Niger Delta. The obtained result indicated that the developed correlation predicted 1652.72 days compared to the actual Oilfield breakthrough time of 1653 days (about 4.53 years). Also, sensitivity study showed that the developed correlation and the integrated reservoir model predictions of oil production rate $\left(q_{o}\right)$, fractional well penetration $\left(h_{p} / h\right)$ and height above perforation-oil column $\left(h_{a p} / h\right)$ on the water breakthrough time $\left(t_{b t}\right)$ were close and resulted in coefficient of determination $\left(R^{2}\right)$ of $0.9697,0.8597$ and 0.9553 , respectively. Furthermore, the results depicted that water coning breakthrough time $\left(t_{b t}\right)$ depends directly on oil production rate $(q)$ and well completion parameters: fractional well penetration $\left(h_{p} / h\right)$ and height above perforation $\left(h_{a p}\right)$. Hence, to delay early water breakthrough in thin oil rim reservoirs, these completion parameters are consideration in vertical wells to achieve optimum oil recovery. Also, the developed correlation can be used as a quick and robust tool to predict water breakthrough time of thin oil rim reservoirs in the Niger Delta.
\end{abstract}

Keywords---- Water coning, Breakthrough time, Integrated reservoir model, Thin oil rim reservoir, Niger Delta

\section{INTRODUCTION}

In the Niger Delta, oil exploration dates back to 1956 when the first commercial accumulation was found. As such, most of the developed fields in the region are matured and the reservoirs (mostly conventional) are in their depletion stage. Meaning, their daily oil production is on the decline. Conversely, as the global and the nation's energy demand increases, thin oil column reservoirs that were considered uneconomical then because of their development and production challenges are exploited. Interestingly, some of these thin oil column reservoirs accumulates potential recoverable reserves that warrant their development and subsequent production. Unfortunately, because of the thiny oil column, thin oil rim reservoirs are prone to early water breakthrough which may come as a result of normal rise of oil water contact, water coning, water fingering, water channeling or a combination (Saad et al., 1992; Ayeni, 2008; Okon et al., 2018). Water coning - the upward movement of water into the production interval occurs when the viscous forces exceeds the gravitation forces in the wellbore. During oil and gas production, the severity of water coning phenomenon includes: reduced depletion mechanism efficiency, early abandonment of the affected well(s), reduced field recovery, reduced field profitability and extra cost for handling produced water (Shaibu et al., 2017). Therefore, to ameliorate the aforementioned challenges during hydrocarbon production, adequate development/production strategies are put in place at the early stage of production. For thin oil rim reservoirs, one of the approaches that would be considered to achieve optimum recovery is to predict the time of water coning occurrence, that is, breakthrough time. Thus, in the literature, several water breakthrough correlations had been developed to predict the occurrence of this production rate sensitivity phenomenon. In the Niger Delta, coning studies in thin oil rim reservoirs have received limited attention. Available studies by Omeke et al. (2010), Onwukwe (2011), Onwukwe et al. (2012), Abdulkarim, (2014), among others used generic reservoir models, experimental design and/or response surface approach to develop coning parameters correlation. Unfortunately, this method does not consider the heterogeneity of the reservoir, hence, it leaves these establish correlations' predictions in doubt. On the other hand, there are correlations based on data from other oil producing regions of the World. However, the varying formation geology, reservoir fluid properties and other factors 
make these existing water breakthrough correlations' prediction for the Niger Delta thin oil rim reservoirs less accurate. Therefore, it is imperative to develop coning parameters correlation based on data and integrated reservoir model from thin oil rim reservoirs in the Niger Delta. In this study, water breakthrough correlation based on production data from existing thin oil rim reservoir in ADX Oilfield in the Niger Delta was developed.

\section{DEVELOPMENT OF BREAKTHROUGH TIME CORRELATION}

Based on numerical (simulation) approach, the correlation presented by Recham et al. (2000) and Permadi (2009) in Equations 1and 2 respectively indicated that water breakthrough time $\left(t_{b t}\right)$ in vertical wells depends on the reservoir, fluid, production rate and completion parameters. The basic parameters in both correlations include: vertical permeability $\left(\mathrm{k}_{\mathrm{v}}\right)$, horizontal permeability $\left(\mathrm{k}_{\mathrm{h}}\right)$, oil viscosity $\left(\mu_{\mathrm{o}}\right)$, oil-water density difference $(\Delta \rho)$, drainage radius $\left(\mathrm{r}_{\mathrm{e}}\right)$, oil production rate $\left(\mathrm{q}_{\mathrm{o}}\right)$, completion interval $\left(\mathrm{h}_{\mathrm{p}}\right)$, oil column $(\mathrm{h})$ and height above completion interval $\left(\mathrm{h}_{\mathrm{ap}}\right)$. Recham et al. (2009) included mobility ratio $(M)$, height below completion $\left(h_{b p}\right)$ and oil formation volume factor $\left(B_{0}\right)$ in dimensionless critical rate $\left(q_{D}\right)$ term. In addition, the completion parameters in the Recham et al. (2000) correlation were expressed in ratio to the oil column $(\mathrm{h})$. Permadi (2009) added porosity $(\varphi)$ and water viscosity $\left(\mu_{\mathrm{w}}\right)$ in his correlation and expressed the completion parameters individually.

$t_{b t}=2996(1+M)^{0.64}\left(\frac{1}{r_{e D}}\right)^{1.11}\left(\frac{1}{q_{D}}\right)^{0.68}\left(1-\frac{h_{p}}{h_{o}}\right)^{0.65}\left(1-\frac{h_{b p}}{h_{o}}\right)^{1.4}\left(1-\frac{h_{a p}}{h_{o}}\right)^{0.99}$

where the terms $M, r_{e D}$ and $q_{D}$ are given as;

$$
\begin{aligned}
& M=\frac{\mu_{o} k_{r w}}{\mu_{w} k_{r o}} ; \quad r_{e D}=\frac{r_{e}}{h_{o}} \sqrt{\frac{k_{v}}{k_{h}}} \text { and } q_{D}=\frac{651.4 \mu_{o} B_{o} q_{o}}{\Delta \rho h_{o}^{2} k_{h}} \\
& t_{b t}=5.3 \times 10^{-2}\left[\frac{\varphi^{1.021} \mu_{w}^{0.511} r_{e}^{0.424} k_{h}^{0.745} h^{3.057}(\Delta \rho)^{0.124}}{\mu_{o}^{0.615} q_{o}^{0.962} k_{v}^{0.859} h_{p}^{0.497} h_{a p}^{0.455}}\right]
\end{aligned}
$$

From the Equations 1 and 2, it is noted that the breakthrough time $\left(t_{b t}\right)$ for vertical well is a function of the parameters expressed mathematically in Equation 3;

$t_{b t}=f\left(\varphi, k_{v}, k_{h}, \mu_{o}, \mu_{w}, \Delta \rho_{o w}, r_{e}, q, h_{p}, h, h_{a p}\right)$

According to Permadi (2009), the Equation 3 can be expanded in the basic form of nonlinear multivariable algebraic expression (Equation 4), which could be further expressed in a linear form using logarithmic transformation, as given in Equation 5;

$$
\begin{aligned}
& t_{b t}=a_{o}\left[\varphi^{\alpha_{1}} k_{v}^{\alpha_{2}} k_{h}^{\alpha_{3}} \mu_{o}^{\alpha_{4}} \mu_{w}^{\alpha_{5}} \Delta \rho_{o w}^{\alpha_{6}} r_{e}^{\alpha_{7}} q^{\alpha_{8}} h_{p}^{\alpha_{9}} h^{\alpha_{10}} h_{a p}^{11}\right] \\
& \log \left(t_{b t}\right)=\log \left(a_{o}\right)+\alpha_{1} \log (\varphi)+\alpha_{2} \log \left(k_{v}\right)+\alpha_{3} \log \left(k_{h}\right)+\alpha_{4} \log \left(\mu_{o}\right)+\alpha_{5} \log \left(\mu_{w}\right)+ \\
& \alpha_{6} \log \left(\Delta \rho_{o w}\right)+\alpha_{7} \log \left(r_{e}\right)+\alpha_{8} \log (q)+\alpha_{9} \log \left(h_{p}\right)+\alpha_{10} \log (h)+\alpha_{11} \log \left(h_{a p}\right)
\end{aligned}
$$

where $a_{0}$ is a coefficient and $\alpha_{1}$ through $\alpha_{11}$ are exponential constants in the breakthrough time equation. These variables $\mathrm{a}_{\mathrm{o}}$ and $\alpha_{1}$ through $\alpha_{11}$ could be determined iteratively using multivariable numerical optimization method. Existing literature mentioned that there are several approaches to perform this iterative estimation, namely, Gauss-Newton, the Marquardt-Levenberg, the Nelder-Mead, the steepest descent, etc. (Wei, 2013; Smyth, 2015; Pashaie et al., 2016; among others). Okon et al. (2015) added that there is a robust and reliable Solver in Microsoft Excel which uses General Reduced Gradient (GRG) as the iterative protocol that can be used to perform multivariable numerical solution.

For the development of the water breakthrough time $\left(t_{b t}\right)$ correlation for thin oil rim reservoirs in the Niger Delta, the expression in Equation 3 was used. These parameters $k_{v}, k_{h}, h_{p}, h$ and $h_{a p}$ in the Equation 3 were modified and presented in ratios as anisotropic $\left(\mathrm{k}_{\mathrm{v}} / \mathrm{k}_{\mathrm{h}}\right)$, fractional well penetration $\left(\mathrm{h}_{\mathrm{p}} / \mathrm{h}\right)$ and height above completion-oil column $\left(\mathrm{h}_{\mathrm{ap}} / \mathrm{h}\right)$. The modification was based on the earlier work by Okon et al. (2018) that breakthrough time $\left(\mathrm{t}_{\mathrm{bt}}\right)$ is mostly influenced by the production rate (q) and completion interval parameters: fractional well penetration $\left(\mathrm{h}_{\mathrm{p}} / \mathrm{h}\right)$ and height above completion oil column $\left(\mathrm{h}_{\mathrm{ap}} / \mathrm{h}\right)$ for vertical wells. Also, the proportionality of breakthrough time on these parameters (as depicted in 
Equation 6) was considered in the formulation of the correlation $\left(t_{b t}\right)$ for thin oil rim reservoirs in the ADX Oilfield. Hence, the Equation 4 becomes (Equation 7);

$$
\left.\begin{array}{l}
t_{b t} \propto \frac{1}{q} \\
t_{b t} \propto \frac{1}{\left(h_{p} / h\right)} \\
t_{b t} \propto \frac{1}{\left(h_{a p} / h\right)}
\end{array}\right\}
$$

In the linear form, the nonlinear Equation 7 is given as;

$$
\begin{aligned}
& \log \left(t_{b t}\right)=\log \left(a_{o}\right)+\alpha_{1} \log (\varphi)+\alpha_{2} \log \left(\mu_{o}\right)+\alpha_{3} \log \left(\mu_{w}\right)+\alpha_{4} \log \left(r_{e}\right)+\alpha_{5} \log (q)+ \\
& \alpha_{6} \log \left(\Delta \rho_{o w}\right)+\alpha_{7} \log \left(k_{v} / k_{h}\right)+\alpha_{8} \log \left(h_{p} / h\right)+\alpha_{9} \log \left(h_{a p} / h\right)
\end{aligned}
$$

The reservoir, fluid and completion parameters required to solve the Equation 8 were obtained from the ADX Oilfield production history data. These obtained parameters are presented in Table 1 . Then, the unknown coefficients $a_{o}$ and $\alpha_{1}$ through $\alpha_{9}$ were solved iteratively using GRG protocol in the Microsoft Excel Solver. The obtained coefficients are presented in Table 3 and the water breakthrough time $\left(t_{b t}\right)$ correlation for thin oil rim reservoirs in the ADX Oilfield is presented in Equation 10. To validate this developed correlation, its prediction was compared with the actual ADX Oilfield water breakthrough time and some authors' correlations prediction. In addition, parametric studies (based on values in Table 2) of oil production rate and completion interval parameters (i.e., $h_{p} / h$ and $h_{a p} / h$ ) on breakthrough time $\left(t_{b t}\right)$ were simulated using the ADX reservoir model (Figure 1). The obtained simulation results were compared with the developed and other authors' correlations predictions (Figures 3 through 5). Additionally, the closeness of these predicted results from the correlations and the simulations run were established using coefficient of determination $\left(\mathrm{R}^{2}\right)$ (Equation 9).

Table 1: The Basic Thin Oil Rim Reservoir's Fluid and Completion Data

\begin{tabular}{ll|ll}
\hline Parameters & Value & Parameters & Value \\
\hline Porosity $(\varphi)$, fraction & 0.168 & Oil Density $\left(\rho_{\mathrm{o}}\right), \mathrm{lb} / \mathrm{ft}^{3}$ & 53.563 \\
Oil Viscosity $\left(\mu_{\mathrm{o}}\right), \mathrm{cP}$ & 0.972 & Water Density $\left(\rho_{\mathrm{w}}\right), \mathrm{lb} / \mathrm{ft}^{3}$ & 64.114 \\
Water Viscosity $\left(\mu_{\mathrm{w}}\right), \mathrm{cP}$ & 0.246 & Oil Production Rate $(\mathrm{q}), \mathrm{lbb} / \mathrm{day}$ & 226.11 \\
Oil Column $(\mathrm{h}), \mathrm{ft}$ & 85.0 & Vertical Permeability $\left(\mathrm{k}_{\mathrm{v}}\right), \mathrm{mD}$ & 2.0074 \\
Completion Interval $\left(\mathrm{h}_{\mathrm{p}}\right), \mathrm{ft}$ & 8.50 & Horizontal Permeability $\left(\mathrm{k}_{\mathrm{h}}\right), \mathrm{mD}$ & 20.074 \\
Drainage Radius $\left(\mathrm{r}_{\mathrm{e}}\right), \mathrm{ft}$ & 2938 & Height above Completion Interval $\left(\mathrm{h}_{\mathrm{p}}\right), \mathrm{ft}$ & 6.00 \\
\hline
\end{tabular}




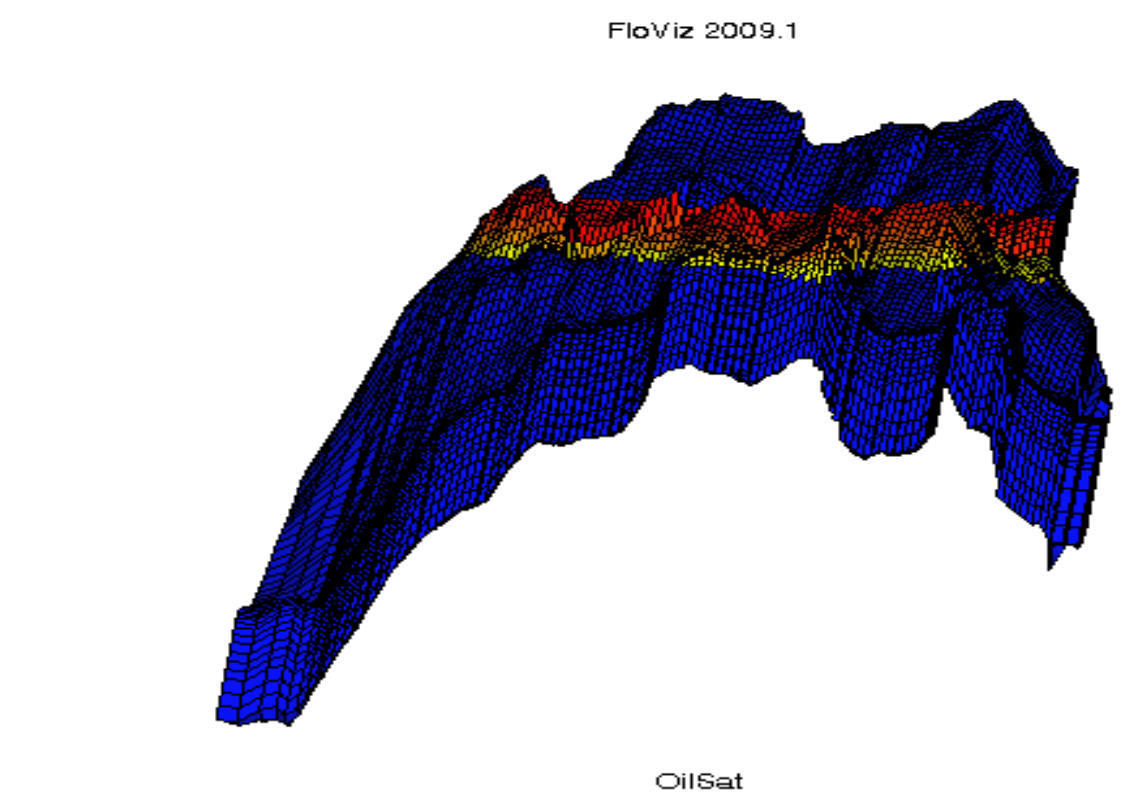

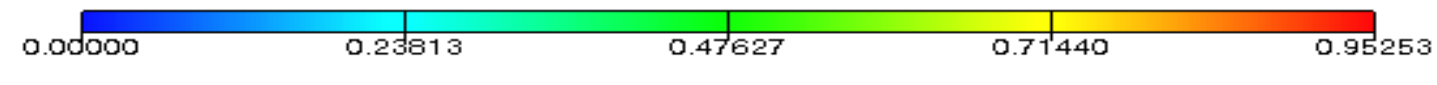

Figure 1: Reservoir Model of ADX Oilfield in the Niger Delta

Table 2: Values for Water Breakthrough Time Parametric Studies

\begin{tabular}{lll}
\hline & Parameters & Values \\
\hline i. & Oil Production Rate $(\mathrm{q}), \mathrm{lbb} /$ day & $250,500,750,1000,2000$ \\
ii. & Fractional Well Penetration $\left(\mathrm{h}_{\mathrm{p}} / \mathrm{h}\right)$ & $0.2,0.3,0.4,0.5,0.6$ \\
iii. & Height above Completion - Oil Column $\left(\mathrm{h}_{\mathrm{ap}} / \mathrm{h}\right)$ & $0.1,0.2,0.3,0.4,0.5$ \\
\hline
\end{tabular}

$$
R^{2}=1-\frac{\sum_{i=1}^{n}\left(t_{b t_{\text {simulated }_{i}}}-t_{b t_{\bmod e_{i}}}\right)^{2}}{\sum_{i=1}^{n}\left(t_{b t_{\text {simulated }_{i}}}-\overline{t_{b t_{\bmod e l}}}\right)^{2}}
$$

Where $t_{b t_{\text {simulated }_{i}}}$ is the simulated breakthrough time, $t_{b t_{\bmod e l_{i}}}$ is the correlation predicted breakthrough time and $\overline{t_{b t_{\bmod e l}}}$ is the average correlation predicted breakthrough time.

\section{DEVELOPED WATER BREAKTHROUGH TIME CORRELATION}

The obtained coefficient and exponential constants for the water breakthrough time $\left(t_{b t}\right)$ using multivariable numerical optimization are presented in Table 3. Based on these obtained values, the developed water breakthrough time $\left(t_{b t}\right)$ for the thin oil rim reservoir in ADX Oilfield is expanded in Equation 10. This established Equation 10 predicted water breakthrough time $\left(t_{b t}\right)$ of 1652.76 days (i.e., about 4.53 years) for the ADX Oilfield. This prediction is comparable with the actual ADX Oilfield water breakthrough time of 1653 days (i.e., about 4.53 years); as noted on the obtained field water-cut performance (Figure 2). On the other hand, Recham et al. (2000) and Permadi (2009) correlations predicted about 450.68 days (i.e., 1.25 years) and 572.36 days (i.e., 1.57 years) respectively for the ADX Oilfield's water breakthrough time $\left(t_{b t}\right)$. These authors' correlation predictions are far less than the actual water breakthrough time $\left(t_{b t}\right)$ for the ADX Oilfield in the Niger Delta. Thus, Equation 10 has a better prediction of the water breakthrough time $\left(t_{b t}\right)$ of the thin oil rim reservoir in ADX Oilfield than the other authors' (i.e., Recham et al., 2000 and Permadi, 2009) correlations. 
Table 3: Coefficients for water breakthrough time correlation (Equation 10)

\begin{tabular}{llcl}
\hline & \multicolumn{1}{c}{ Parameters } & Coefficients & Values \\
\hline i. & Proportionality Constant & $\mathrm{a}_{\mathrm{o}}$ & 1195 \\
ii. & Porosity, $(\varphi)$ & $\alpha_{1}$ & 0.1747 \\
iii. & Oil Viscosity, $\left(\mu_{\mathrm{o}}\right)$ & $\alpha_{2}$ & 0.1997 \\
iv. & Water Viscosity, $\left(\mu_{\mathrm{w}}\right)$ & $\alpha_{3}$ & 0.1805 \\
v. & Drainage Radius, $\left(\mathrm{r}_{\mathrm{e}}\right)$ & $\alpha_{4}$ & 0.0969 \\
vi. & Oil Production Rate, $(\mathrm{q})$ & $\alpha_{5}$ & -0.1645 \\
vii. & Oil-water Density difference, $(\Delta \rho)$ & $\alpha_{6}$ & 0.2190 \\
viii. & Anisotropy Ratio, $\left(\mathrm{k}_{\mathrm{v}} / \mathrm{k}_{\mathrm{h}}\right)$ & $\alpha_{7}$ & 0.1594 \\
ix. & Fractional Well Penetration, $\left(\mathrm{h}_{\mathrm{p}} / \mathrm{h}\right)$ & $\alpha_{8}$ & -0.1764 \\
x. & Height above completion-Oil Column, $\left(\mathrm{h}_{\mathrm{ap}} / \mathrm{h}\right)$ & $\alpha_{9}$ & -0.1718 \\
\hline
\end{tabular}

$t_{b t}=1195\left[\frac{\varphi^{0.1747} \mu_{o}^{0.1997} \mu_{w}^{0.1805} r_{e}^{0.0969} \Delta \rho_{o w}^{0.2190}\left(k_{v} / k_{h}\right)^{0.1594}}{q^{0.1645}\left(h_{p} / h\right)^{0.1764}\left(h_{a p} / h\right)^{0.1718}}\right]$

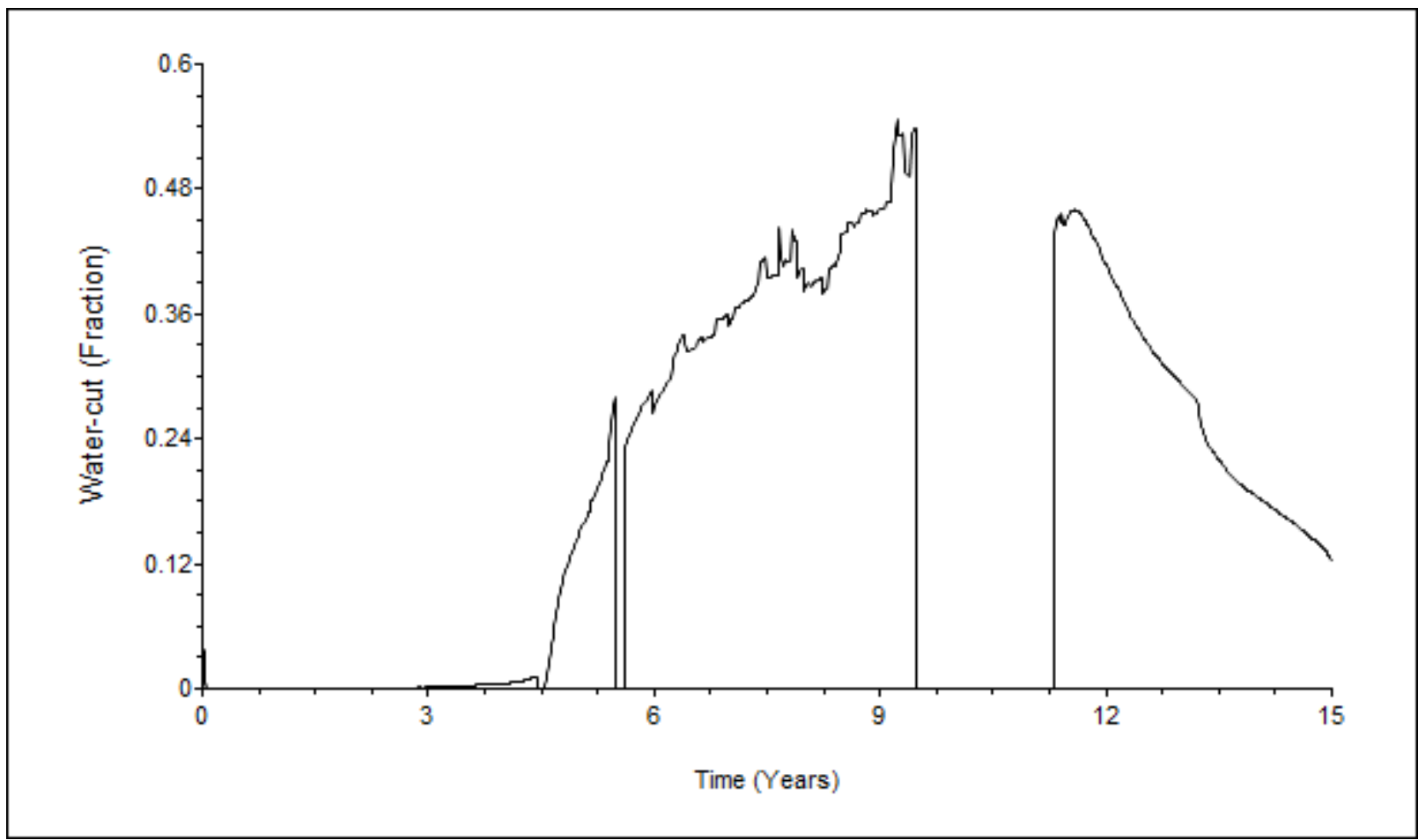

Figure 2: Water-cut Performance History of the ADX Oilfield

The parametric studies of oil production rate $(\mathrm{q})$ and completion interval ratios (i.e., fractional well penetration $\left(\mathrm{h}_{\mathrm{p}} / \mathrm{h}\right)$ and height above completion-oil column; $\left.\left(\mathrm{h}_{\mathrm{ap}} / \mathrm{h}\right)\right)$ on water breakthrough time $\left(\mathrm{t}_{\mathrm{bt}}\right)$ are presented in Figures 3 through 5. The obtained results indicated that the developed water breakthrough time $\left(t_{b t}\right)$ correlation predictions were close to the obtained ADX reservoir model simulation results. The obtained predictions from the developed correlation and the reservoir model simulation resulted in coefficient of determination $\left(\mathrm{R}^{2}\right)$ of $0.9697,0.8597$ and 0.9553 for oil production rate $\left(\mathrm{q}_{\mathrm{o}}\right)$, fractional well penetration $\left(\mathrm{h}_{\mathrm{p}} / \mathrm{h}\right)$ and height above completion-oil column $\left(\mathrm{h}_{\mathrm{ap}} / \mathrm{h}\right)$, respectively. These obtained coefficients of determination indicated that the developed water breakthrough time $\left(\mathrm{t}_{\mathrm{bt}}\right)$ correlation for the thin oil rim reservoir would give a better prediction of water coning breakthrough time for the ADX Oilfield.

Again, in the Figures 3 through 5, the parametric predictions by the Recham et al. (2000) and Permadi (2009) correlations were extremely less than the obtained reservoir model simulation results. This observation would be attributed to the quantity and scope of data upon which these correlations were based (Okon and Appah, 2016). Hence, the data upon which these correlations are based were from generic reservoir models not integrated field reservoir model(s). Secondly, the authors did not take into consideration the proportionality of breakthrough time $\left(t_{b t}\right)$ on fractional 
well penetration $\left(h_{p} / h\right)$ and height above completion-oil column $\left(h_{a p} / h\right)$ in their models. Recham et al. (2000) expressed these parameters as directly proportional to breakthrough time $\left(t_{b t}\right)$ while Permadi (2009) expanded completion interval $\left(h_{p}\right)$, height above completion interval $\left(h_{a p}\right)$ and oil column $(h)$ separately in his model. These disparities would also affect the water breakthrough time $\left(t_{b t}\right)$ prediction of these correlations; especially in oil column sensitive reservoirs like thin oil rim. Furthermore, the comparison of these correlations predictions indicated that Recham et al. (2000) correlation resulted in coefficients of determination $\left(\mathrm{R}^{2}\right)$ of $0.0163,0.0069$ and 0.0147 for oil production rate $\left(\mathrm{q}_{\mathrm{o}}\right)$, fractional well penetration $\left(\mathrm{h}_{\mathrm{p}} / \mathrm{h}\right)$ and height above completion-oil column $\left(\mathrm{h}_{\mathrm{ap}} / \mathrm{h}\right)$ respectively. While, the Permadi (2009) correlation resulted in coefficients of determination $\left(\mathrm{R}^{2}\right)$ of $0.0178,0.0071$ and 0.0167 for oil production rate, fractional well penetration $\left(h_{\mathrm{p}} / \mathrm{h}\right)$ and height above completion-oil column $\left(\mathrm{h}_{\mathrm{ap}} / \mathrm{h}\right)$ respectively. These obtained low coefficients of determination $\left(\mathrm{R}^{2}\right)$ from Recham et al. (2000) and Permadi (2009) correlations were attributed to the mentioned drawbacks in the model. Based on the obtained predictions and established coefficients of determination $\left(\mathrm{R}^{2}\right)$, the developed correlation (Equation 10) would give more realistic water coning breakthrough time for thin oil rim reservoir in ADX Oilfield in the Niger Delta than Recham et al. (2000) and Permadi (2009) correlations

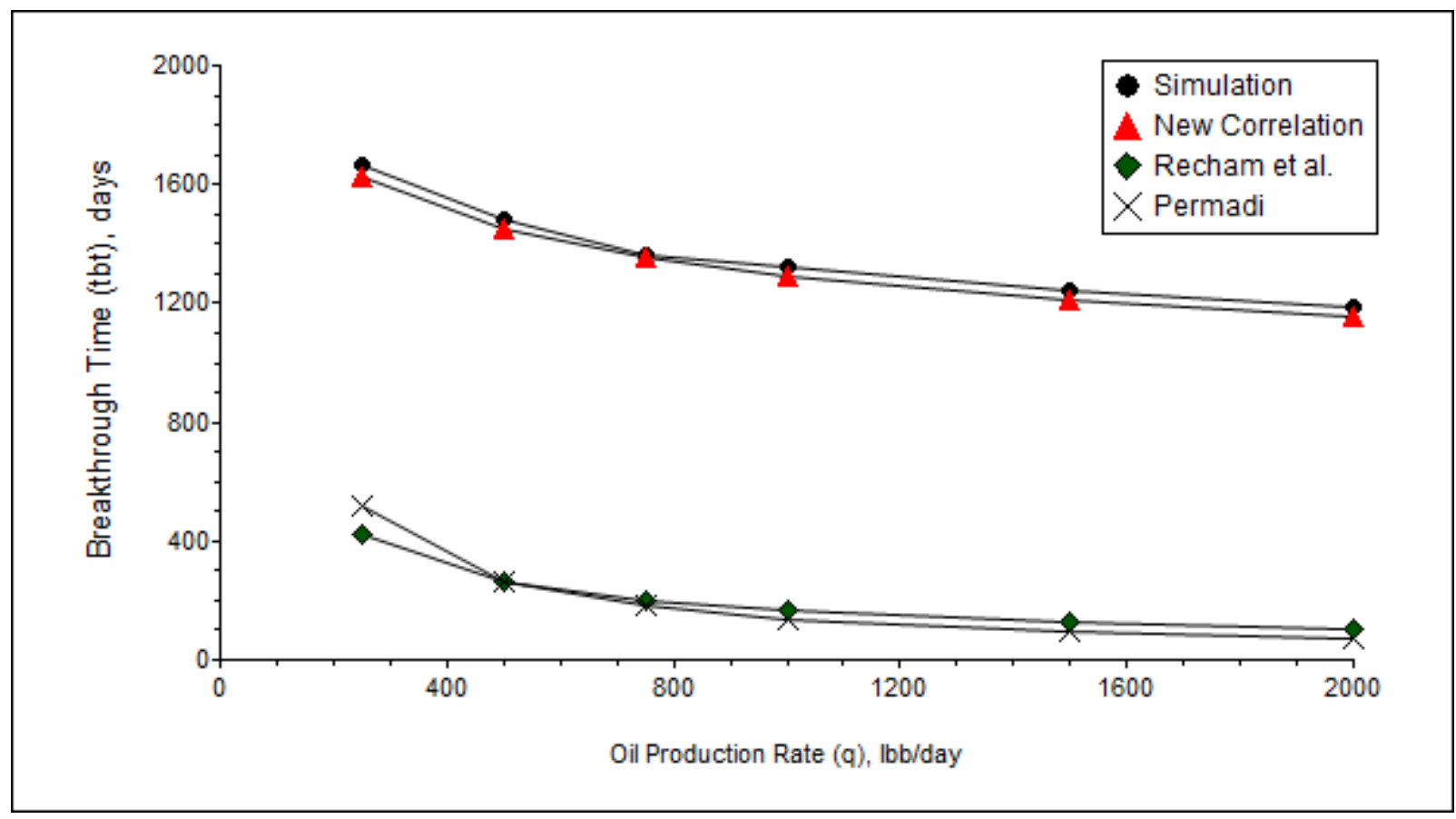

Figure 3: Breakthrough Time against Oil Production Rate 


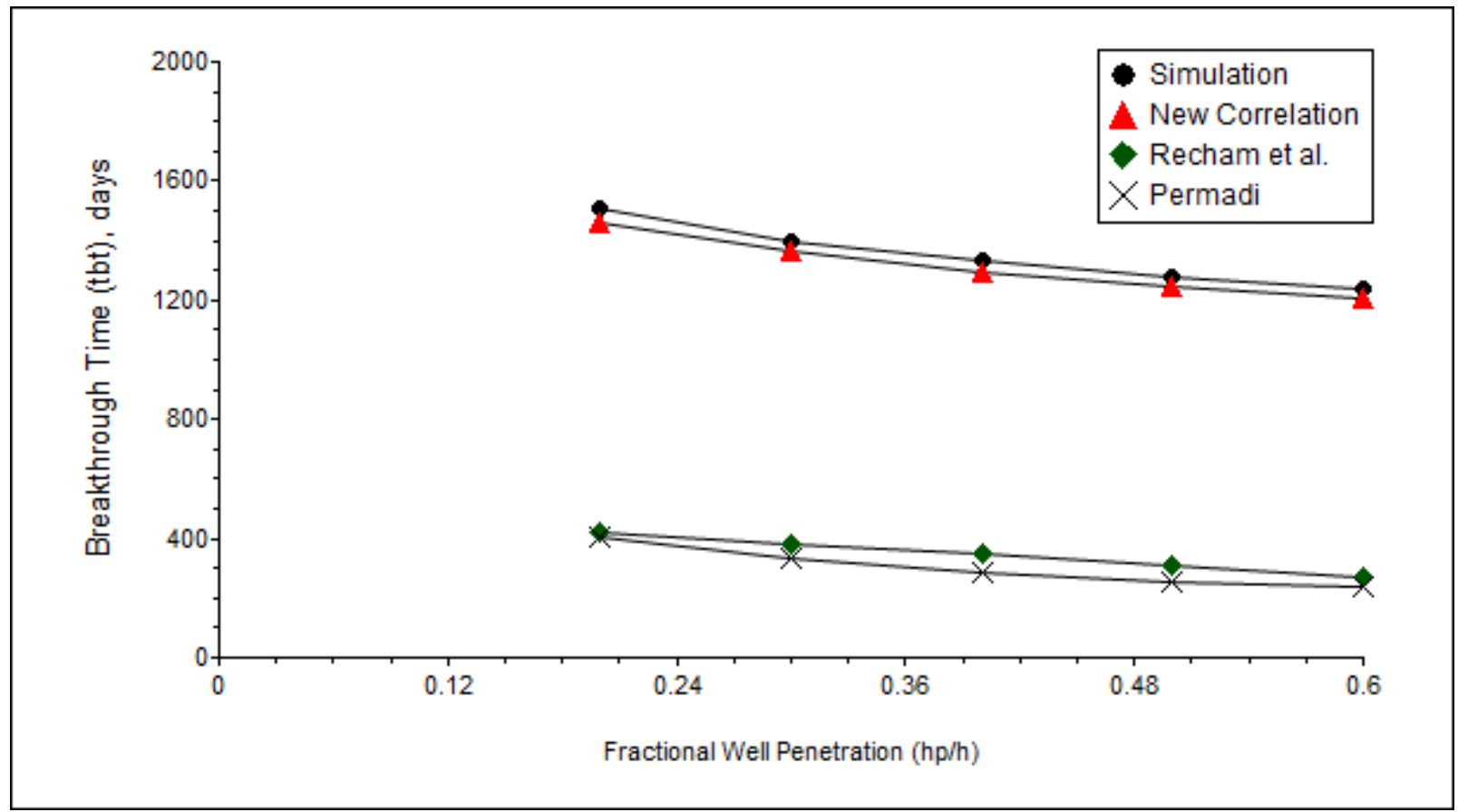

Figure 4: Breakthrough Time against Fractional Well Penetration

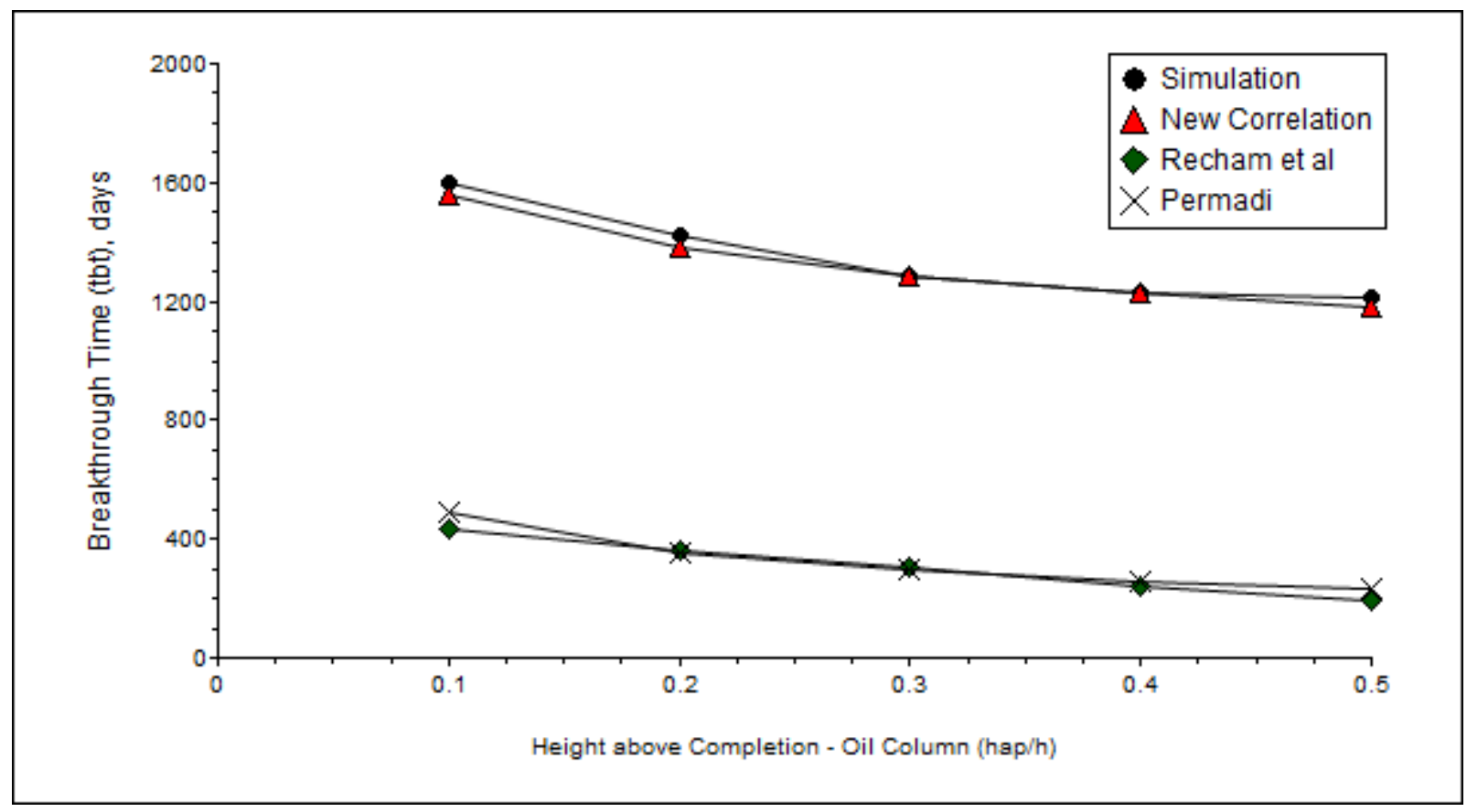

Figure 5: Breakthrough Time against Height above Completion-Oil Column

\section{CONCLUSION}

In thin oil rim reservoirs, early water production from coning phenomenon is inevitable due to its thiny oil spread column. As such, developing these reservoirs require assiduous planning and development strategy to be put in place. One of the factors to be considered is the expected time of water coning occurrence - breakthrough time. In the Niger Delta, some breakthrough time correlations had been developed from generic reservoir models and/or experimental design approach. Unfortunately, the reliability of these correlations' predictions for thin oil rim reservoirs in the Niger Delta is in doubt, as they did not consider the heterogeneity of the reservoir. In this study, water breakthrough time correlation was developed based on integrated reservoir model of a thin oil rim reservoirs in the Niger Delta and the following conclusions were drawn: 
i. the developed correlation prediction and the actual Oilfield water breakthrough time were comparable, that is, 1652,76 days and 1653 days (i.e., about 4.53 years);

ii. the developed correlation and the integrated reservoir model predictions of oil production rate $\left(\mathrm{q}_{\mathrm{o}}\right)$, fractional well penetration $\left(\mathrm{h}_{\mathrm{p}} / \mathrm{h}\right)$ and height above perforation-oil column $\left(\mathrm{h}_{\mathrm{ap}} / \mathrm{h}\right)$ sensitivity on water breakthrough time $\left(t_{b t}\right)$ were close and resulted in coefficient of determination $\left(\mathrm{R}^{2}\right)$ of $0.9697,0.8597$ and 0.9553, respectively; and

iii. for vertical wells, water coning breakthrough time $\left(t_{b t}\right)$ depends directly on oil production rate $(q)$ and well completion parameters: fractional well penetration $\left(\mathrm{h}_{\mathrm{p}} / \mathrm{h}\right)$ and height above perforation $\left(\mathrm{h}_{\mathrm{ap}}\right)$.

Hence, for vertical wells completion in thin oil rim reservoirs in the Niger Delta, consideration of fractional well penetration and height above perforation should be a major concern to mitigate early water breakthrough. Thus, the developed correlation can be used as a quick tool to predict water breakthrough time for thin oil rim reservoirs in the Niger Delta.

\section{Nomenclature}

$t_{b t}=$ breakthrough time, days

$\Delta \rho_{o w}=$ water-oil density difference, $l b / f t^{3}$

$\mu_{o}=$ oil viscosity, $c p$

$\mu_{w}=$ water viscosity, $c p$

$r_{w}=$ wellbore radius, $f t$

$r_{e}=$ drainage radius, $f t$

$h=$ oil column, $f t$

$h_{p}=$ height of completion interval, $f t$

$k_{v}=$ vertical permeability, $m d$

$k_{h}=$ horizontal permeability, $m d$

$B_{o}=$ oil formation volume factor, $r b / s t b$

$M=$ mobility ratio

$g$ = gravity constant, $f t / h r^{2}$

$h_{a p}=$ height above completion interval, $f t$

$h_{b p}=$ height below completion interval, $f t$

$q_{o}=$ oil production rate $s t b / d$

$q_{D}=$ dimensionless critical rate

$r_{e D}=$ dimensionless drainage radius

$k_{r o}=$ oil relative permeability at $S_{w c}$

$k_{r w}=$ water relative permeability at $S_{o r}$

$S_{w c}=$ connate water saturation

$S_{\text {or }}=$ residual oil saturation

\section{REFERENCES}

- Abdulkarim, M. A. (2014). Development of Coning Correlations for Oil Rim Reservoirs using Experimental Design and Response Surface Methodology. Unpublished M.Sc. Thesis, African University of Science and Technology, Abuja, Nigeria.

- Ayeni, K. B. (2008). Empirical Modeling and Simulation of Edgewater Cusping and Coning. PhD. Dissertation, Texas A\&M University, USA.

- Okon, A. N. and Appah, D. (2016). Neural Network Models for Predicting Wellhead Pressure - Flow Rate Relationship for Niger Delta. Journal of Scientific Research and Reports, 12(1): 1-14.

- Okon, A. N., Appah, D. and Akpabio, J. U. (2018). A Critical Evaluation of Water Coning Correlations in Vertical Wells. American Journal of Science, Engineering and Technology, 3(1): 1-9. 
- Okon, A. N., Udoh, F. D. and Appah, D. (2015). Empirical Wellhead Pressure - Production Rate Correlations for Niger Delta Oil Wells. Paper presented at the Society of Petroleum Engineers Nigeria Annual International Conference and Exhibition, Lagos, Nigeria, 4-6 August, pp. 1-17.

- Omeke, J. E., Livinus, A., Uche, I. N., Obah, B. and Ekeoma, E. (2010). A Proposed Cone Breakthrough Time Model for Horizontal Wells in Thin Oil Rim Reservoirs. Paper presented at the 34th Annual Society of Petroleum Engineers International Conference and Exhibition, Tinapa, Calabar, Nigeria, 31 July-7 August, pp. $1-11$.

- Onwukwe, S. I. (2011). A Novel Approach for Estimating Critical Rate and Horizontal Well Placement in Oil Rim Reservoirs. Unpublished PhD Thesis, Federal University of Technology, Owerri, Nigeria.

- Onwukwe, S. I., Obah, B. and Chukwu, G. A. (2012). A Model Approach of Controlling Coning in Oil Rim Reservoirs. Paper presented at the Nigerian Annual Technical Conference and Exhibition of Society of Petroleum Engineers, Abuja, 6-8 August, pp. 1-10.

- Pashaie, M., Sadeghi, M. and Jafarian, A. (2016). Artificial Neural Networks with Nelder-Mead Optimization Method for solving Nonlinear Integral Equations. Journal of Computer Science and Application, 8(1): 1-20.

- Permadi, A. K. (2009). New Empirical Correlation for Predicting Water Breakthrough Time of a Vertical Well in a Bottom-Water Reservoir. Jurnal Teknologi Mineral. https://petroleumstudies.files.wordpress.com/2009/03/11.pdf. Accessed 10th May, 2017.

- Recham, R., Osisanya, S. O. and Touami, M. (2000). Effect of Water Coning on the Performance of Vertical and Horizontal Wells - A Reservoir Simulation Study of Hassi R'mel Field, Algeria. Paper presented at Society of Petroleum Engineers/Petroleum Society of Canadian Institute of Mining, Metallurgy and Petroleum International Conference on Horizontal Well Technology, Calgary, Alberta, Canada, 6-8 November, pp. 1-12.

- Saad, S. M., Darwich, T. and Asaad, Y. (1995). Water Coning in Fractured Basement Reservoirs. Paper presented at Society of Petroleum Engineers Middle East Oil Show, Bahrain, 11-14 March, pp. 1-10.

- Shaibu, R., Klewiah, I., Mahamah, M. A., Acquah, I. E., Cobbah, C. and Asiedu, S. W. (2017). An Intelligent Well Approach to Controlling Water Coning Problems in Horizontal Production Wells. International Journal of Engineering and Technical Research, 6(1): 317-323.

- Smyth, G. K. (2015). Optimization and Nonlinear Equations. Wiley StataRef: Statistics Reference Online. pp. 19. doi: 10.1002/9781118445112.stat05030.pub2.

- Wei, J. (2013). Multivariate Numerical Optimization. Lecture Note. https://studentportalen.uu.se/uusp-fileareatool. Accessed: 1st June, 2018. 